\title{
The Difficult Case of Persuading Women: Experimental Evidence from Childcare*
}

\author{
Vincenzo Galasso (Universita' Bocconi, Dondena and CEPR) \\ Paola Profeta (Universita' Bocconi and Dondena) \\ Chiara Pronzato (Universita' di Torino and Collegio Carlo Alberto) \\ Francesco Billari (Oxford University)
}

October 2013

\begin{abstract}
Gender stereotypes are well established also among women. Yet, a recent literature suggests that learning from other women experience about the effects of maternal employment on children outcomes may increase female labor force participation. To further explore this channel, we design a randomized survey experiment, in which 1500 Italian women aged 20 to 40 are exposed to two informational treatments on the positive consequences of formal childcare on children future educational attainments. Surprisingly, we find that women reduce their intended labor supply. However, this result hides strong heterogenous effects: high educated non-mothers are persuaded by the informational treatments to increase their intended use of formal child care (and to pay more); whereas low educated non-mothers to reduce their intended labor supply. These findings are consistent with women responding to monetary incentive and/or having different preferences for maternal care. These heterogenous responses across women send a warning signal about the true effectiveness - in terms of take up rates - of often advocated public policies regarding formal child care.
\end{abstract}

Keywords: gender culture, female labour supply, education

JEL Classification: J2, J16, J13, J18, Z1,C99

*Francesco Billari, Oxford University, Department of Sociology, Manor Road, Oxford, francesco.billari@sociology.ox.ac.uk; Vincenzo Galasso, Università Bocconi, Department of Policy Analysis, Via Röntgen 1, Milan; Paola Profeta, Università Bocconi, Department of Policy Analysis, Via Röntgen 1, 20136 Milan (Italy), paola.profeta@unibocconi.it; Chiara Pronzato, Università di Torino, Department of Economics and Statistics, Lungo Dora Siena 11, 10153 Torino, chiaradaniela.pronzato@unito.it. We thank participants at conferences PAA 2013, ESPE 2013, EALE 2013, CESifo-Conference on Social Protection 2013, Alp-Pop 2013, workshop Dondena-Bank of Italy 2012, and seminars at the University of Lugano, Collegio Carlo Alberto, Bicocca University, University of Turin. All remaining errors are ours. 


\section{Introduction}

Gender gaps still dominate the economic scenario in many countries. Labour market differences between men and women are wide in European countries: in 2012 the employment rate for men in the EU-27 was 74.6\%, compared with $62.4 \%$ for women (Eurostat statistics). There are however considerable disparities across European countries: the highest female employment rate is in Iceland at $79.1 \%$ ( $84.4 \%$ for men), and remains above $70 \%$ in Scandinavian countries, while it is only $50.5 \%$ in Italy ( $71.6 \%$ for men), and even less in Greece and Malta. Non family friendly institutions in the labor market and in family policy have often been blamed for these disappointing outcomes (Del Boca, 2002; Del Boca et al., 2009).

Yet, cultural aspects also play an important role in explaining gender gaps (Fernandez, 2007). The social evaluation of women's and men's roles in society, of their responsibilities in the family context, and of their position in the labour market largely influences labour market participation, education decisions, career prospects and even fertility (Pfau-Effinger, 2000). And this gender culture is just as established among men as among women. ${ }^{1}$ One of the most pervasive gender stereotype relates to maternal employment and child care. ${ }^{2}$ Women are seen (and see themselves) as the better provider of care for their children, and thus refrain from delegating child care. At the same time, they may be skeptical about their chances of being successful both as mothers and in their working

\footnotetext{
${ }^{1}$ According to data from the European Values Survey (2008), in Italy a high percentage of both men and women ( $71 \%$ and $63 \%$ respectively) agree with the statement "A job is alright but what women really want is a home and children". Only $18 \%$ of both men and women agree with the statement "In general fathers are as well suited to look after their children as mothers". Gender culture does vary across countries, however, men and women preferences remain relatively similar within country. For instance, in Denmark $12 \%$ of men and $11 \%$ of women agree with the first statement, and $38 \%$ of men and $48 \%$ of women with the second one.

${ }^{2}$ Looking again at the European Values Survey, in Italy only $14 \%$ of men and $23 \%$ of women agree with the statement "A working mother can establish just as warm and secure a relationship with her children as a mother who does not work". The respective percentages in Denmark are $54 \%$ for men and $64 \%$ for women.
} 
career.

Unfortunately, this gender culture is persistent, since preferences tend to be trasmitted from one generation to the next (Moen et al., 1997). This may happen because parents have a taste for transmitting their values to their offspring, or because, regardless of their own preferences, parents choose to teach their children how to best respond to the predominant culture ${ }^{3}$. Knowledge and information may however play a role in breaking this intergenerational transmission mechanism of gender stereotypes. Fogli and Veldkamp (2011) show that, as women learn about the effects of maternal employment on children - by observing nearby employed women of the previous generation - they realize that these effects need not to be negative, and, moreover, that they can manage to keep both a job and a family. As a result, female participation rates increase. Thus, the persistence of gender stereotypes may depend on women lacking information, for instance, on the consequences of their participation in the labor market on their children psychological and educational outcomes ${ }^{4}$.

In this paper, we provide a direct test of the effect of a public policy, which consists in releasing information to women about the benefits of using formal child care on their labor market and on child care intended behaviors. We design a survey experiment on a sample of Italian women of reproductive age. Our goal is to study whether providing information on the positive consequences of formal child care on children outcomes - thereby increasing their knowledge on this issue - has a causal impact on women's decisions of using formal child care, of participating in the labour market, and of how to arrange the child care within the family. In particular, we expect this positive information to

\footnotetext{
${ }^{3}$ On the positive side, cultural aspects may also induce a virtuous circle. In fact, Fernandez et al. (2004) show that (white) men, whose mothers worked while they were growing up, tend to be married to working women.

${ }^{4}$ The relation between maternal employment and family outcomes, such as the stability of marriage and children cognitive attainments, has been analyzed by a large literature (see Poortman, 2005 and Kalmijn and Poortman, 2006 and Cuhna et al., 2010).
} 
reduce possible parental skepticism about the use of formal child care centers, and thus to promote its adoption. ${ }^{5}$ Additionally, a more extensive utilization of formal child care could allow mothers, who represent - in Italy, but also elsewhere - the main provider of parental care, to have more time to dedicate to market activity. Several studies have indeed shown that public kindergartens have a positive impact on maternal employment (see Cascio, 2009, Gelbach, 2002, Lefebvre and Merrigan, 2008, and Del Boca and Vuri, 2007 ${ }^{6}$; and these results are expected to be stronger for more educated mothers, who are more likely to choose center-based childcare than alternative care, such as unpaid care or paid care by a nanny (Del Boca and Vuri, 2007; Suarez, 2013). Finally, Italy represents a perfect place, where to study the impact of information on stereotypes, due to existence of a strong gender culture ${ }^{7}$.

Our informational treatment consists of two types of persuasive communication $^{8}$ - namely, text messages and a video - regarding the effectiveness of formal child care in increasing children future educational attainments. The informational content of our treatment borrows from recent studies that have shown day-care attendance to have positive effects on children' educational outcomes (Felfe and Lalive, 2010; Havnes and Mogstad, 2011, Brilli et al., 2011). Formal childcare has been recognized to play a positive role particularly for children from disadvantaged families (Carneiro and Heckman, 2003). Instead, a beneficial effect is not necessarily obtained by increasing maternal time: a recent study by Dustmann and Schonberg (2012) shows that the expansion in mother's leave coverage did not improve their children's educational and labor

\footnotetext{
${ }^{5}$ The role of information and persuasive communication on changing individuals' opinions has been addressed in several contexts: see Cochran and Chamlin (2005) for the case of capital punishment, Avitabile (2012), Dupas (2009) and Avery et al. (2006) for health related issues.

${ }^{6}$ Note however that no effect is found in Fitzpatrick (2012).

${ }^{7}$ See the European Values Survey data reported in footnote 1 and 2.

${ }^{8} \mathrm{As}$ it has been recognized in several fields, such as economics, marketing, psychology and communications, information may be delivered through persuasive communication (Della Vigna and Gantzkow, 2010).
} 
market outcomes ${ }^{9}$.

In our experiment, a sample of 1,500 Italian women between 20 and 40 years old is randomly assigned to three groups. The first groups is treated with a set of text messages, i.e., women in this group saw on screen text messages, which state the benefits of day-care attendance. The second group is treated with a videomessage, i.e., women were shown a video featuring six months-to- three years old children doing activities at a day-care center, while a background voice read the same messages on the benefits of day-care attendance, as shown to the first group. The third - control - group was not treated, and hence did not receive any information. Before the treatment, background individual characteristics, such as age, marital status, number and age of children, nationality, education, level and work activity were asked. After the treatment, we asked all women several questions, related to different topics, which represent our outcomes of interest. The questions include: (i) their intention to use formal child care, as well as their willingness to pay for it; (ii) their intended participation in the labor market, both on the extensive and on the intensive margin; and (iii) other family arrangements.

Our experimental results suggest that information on the educational advantages obtained by children who attended child care reduces women intended labor supply. This surprising result hides strong heterogenous effects ${ }^{10}$. Among non-mothers, who may expect to have a child, and thus envisage their future childcare and labor decisions, education attainments draw a clear divide. While

\footnotetext{
${ }^{9}$ The relation among maternal time, use of formal child-care and children outcomes is still debated. Previous contributions have shown that substituting maternal time with other child care providers may deliver negative results for children skills, thus inducing a negative relationship between maternal employment and child development (Baker et al, 2008, Baum, 2003, Ruhm, 2004). However, when maternal time is substituted with formal childcare the adverse effect of maternal employment on children cognitive outcomes disappears (Bernal, 2008, Bernal and Keane, 2010 and 2011).

${ }^{10}$ Interestingly, previous studies have concluded that different individuals may react to identical messages in quite different ways (Bostrom, 1983) and thus individual characteristics turn out to be crucial when assessing the persuading impact of communication on targeted groups.
} 
high educated women respond to the informational treatment by increasing their intended use of formal child care, and are also willing to pay more for it, low educated women do not modify their formal child care decision, but reduce their intended labor supply. A simple theoretical model, introduced at section 4, helps to interpret these, somewhat surprising, results. Educational attainments may depend on women's working ability type and on their identity (see Akerloff and Kranton, 2000). We consider that women are either career oriented or of maternal type. High ability and career oriented women are more likely to become educated - and thus to earn a high wage. Information about the benefits of using formal child care thus re-enforce their decision of sending their children to formal care. Low ability and maternal type will instead be more likely to remain uneducated, and thus to earn low wages. To them, new knowledge about the benefits of formal care - and in general about the relevance of early childhood investments - will strengthen their own maternal role. This may be due both to their preferences for maternal care and to the monetary incentives related to their low wages. The existence of heterogenous responses across women should send a warning signal about the true effectiveness - in terms of take up rates of often advocated public policies regarding formal child care.

The paper is organized as follows: the next section describes the experimental design; section 3 presents the results of the empirical analysis; section 4 introduces a stylized model of women's decisions, and section 5 concludes. The proofs of the two propositions at section 4 are in the appendix.

\section{Experimental design}

To persuade women to use formal child care - and possibly to increase their labor supply, we choose to release information on the advantage in the future educational obtainments for children, who attend formal child care. More specifically, 
women in the treatment groups receive the following three pieces of information, taken from scientific publications ${ }^{11}$, as a text or from a background voice in a video:

Information I A study conducted on ten years old Germans shows that children who attended formal child care are more independent, socialize more with other children, and use a more appropriate language, when compared to children who stayed at home.

Information II A research on thirty years old Norwegians shows that those who attended formal child care have a higher probability of going to college, earn more, and have a lower probability to be on welfare.

Information III Also in Italy, thanks to data collected by the National Institute for the Evaluation of the Educational System, a positive effect of attending formal child care emerges. In second grade, children who attended formal child care have better results in Italian tests than others.

These messages thus emphasize the salience of early life investments in the future education attainments of children, and, in particular, the role played by formal child care. We provide these informations with two different treatments. For one treatment group, these (three) messages are released in an on-screen text format, which helps to single out their informative content. For the second group, the messages are instead read by a background voice in a video showing images of children doing several activities at a formal child care institution. In this case, the informational content is accompanied by images and sounds, which are likely to solicit also an emotional response.

Our online sample consists of 1,503 Italian women aged between 20 and 40 years. All women answered to an online survey. A survey agency, Carlo Er-

\footnotetext{
${ }^{11}$ Information I is from Felfe and Lalive (2010); Information II from Havnes and Mogstad (2011); and Information III from Brilli et al. (2011).
} 
minero \& Co., was contacted to run the online survey. The agency exploited an existing panel of 20,000 people with internet access from home, who had previously agreed to participate to online surveys on social issues (environment, labor, politics) and marketing (products and brands). The agency randomly sampled 3,300 women 20-40 years old who were then invited by e-mail to answer a survey on child care. Those who initially agreed to be interviewed were immediately selected and randomly assigned to the different groups. Among the 2,066 women who agreed to fill the questionnaire, 221 interviews did not conclude the interview, while 342 were automatically dropped by the survey company, as the required sample size for each group (mothers and non-mothers of different age classes) had been reached. The survey took place in November 2011.

In an initial part of the survey, women were asked questions about their individual characteristics (age, location, education, fertility history, marital status, occupation). Their average age is 32 years, $67 \%$ of the interviewed is in a stable relation, $54 \%$ are mothers, $39 \%$ have tertiary education, $62 \%$ are employed. Among the mothers, almost half of them have their youngest child of age 0 to 3. A summary of their characteristics is at table 1 .

In the second part of the survey, the interviewed women were randomly assigned to three different groups. As shown in table 2, these three groups are balanced in their observable characteristics, with the exception of employment status and political orientations (right and left leaning). However, these differences (but employment status at a 10\% level) disappear in the sample of non-mothers (see table 3), which we will use in most of our empirical analysis . Women in the first group were treated with a text message, which showed in three subsequent pages the three pieces of information reported above. Women in the second group were exposed to a 60 seconds video showing a group of children doing various activities, such as playing, painting, dancing and hav- 
ing lunch, at a child care facility, while a (professional) background voice reads the three pieces of information reported above ${ }^{12}$. Women in the third group (the control group) instead did not receive any information. Women in the treatment groups were then asked whether they already knew the information released, whether they find it credible, and how much they liked it.

In the third part of the survey, all women were asked questions on their willingness to pay for formal child care, on their labor supply intentions (both for the extensive and intensive margin), as well as on their preferences for different family arrangements. Only non-mothers were asked about their potential future use of formal child care. This is because most mothers already had to make an irreversible choice about the use of formal child care; whereas non-mothers expecting to have a baby in the future ( $91 \%$ in our sample) still had to face this decision. Responses came in different forms (see table A1). When asked "Do you agree with the message?", the possible answers were in categories (Strongly agree, Agree, Nor agree nor disagree, Disagree, Strongly disagree). The question on the desired working status allowed for a binary response $(1=$ Work or $0=$ No work). Continuous measures were used for "How much did you like the text/video?", from 1 to 9 , and for the desired weekly hours of work, from 0 to 99 . Responses that allowed for categories were rearranged to be binary (see table 1), while binary response or continuous measures were not transformed.

For the external validity of the experiment, it is of interest to compare the average characteristics of the women in our sample with the average characteristics of women between 20 and 40 years old in the Italian section of the European Survey on Living and Income conditions, a representative Italian household survey $^{13}$. Women in the two samples are of similar age and contribution to the

\footnotetext{
${ }^{12}$ The video is available upon request, but could not be made freely available on line for ethical issues.

${ }^{13}$ Table A2 in the Appendix provide a comparison of our sample, with the corresponding European Survey on Living and Income conditions for the year 2010.
} 
disposable household income. A difference emerges in their average level of education, since $39 \%$ of women in our sample have tertiary education versus only $25 \%$ in the Italian representative data. Along these lines, the women in our sample tend to work more ( $62 \%$ versus $57 \%)^{14}$. For the sample of non-mothers differences between our sample and the Italian representative data disappear, except for education, whose differences are largely explained by the online nature of our sample, as online panels typically feature more high educated respondents.

\section{Empirical Analysis}

The average effects of our experiment on the women decisions are reported at table 4. These results seem to suggest that our treatments had little power in persuading women to pay more for formal child care, neither they affected their desired working status. However, a surprising finding emerges: women exposed to the video treatment reduced their desired hours of work from 19.2 hours per week to 17.1. This effect does not emerge with the text treatment, which instead induced a reduction in the preference for the use of grandparents for child care (from $18 \%$ of favorable women to $13.9 \%$ ).

To appreciate the effect of our treatment on the potential use of formal child care, we turn to non-mothers, to whom only this question was asked. In fact, while almost all non-mothers in our sample (91\%) expressed their desire to have at least one child during their life (and $68 \%$ in the next three years), and thus expected to face this decision in the (near) future, this choice will most likely no longer be salient for already mothers. The text treatment proved to be very effective in raising the share of non-mothers willing to use formal child care facilities, which increased from $44 \%$ to $58.5 \%$, while the video treatment had no

\footnotetext{
${ }^{14}$ Although household monthly income is difficult to compare, being measured as gross labor income in the European Survey on Living and Income conditions, and as total net income in our sample, a rough comparison, based on a 30\% average tax rate, suggests that women have a slightly higher net income in our sample.
} 
significant impact. This amounts to a persuasion rate of about $25.8 \%$, which is in the upper tail of the empirical distribution according to DellaVigna and Gentzkow (2009). Consistently, the text treatment increased also the willing to pay for formal child care, from Euro 328 per month to Euro 361 (see table 4). Despite this appreciation for formal child care, however, non-mothers were strongly induced to reduce their labor supply - both on the extensive margin (from $89 \%$ of women willing to work to around $81 \%$ ) and on the intensive margin (from 23 hours per week to 20.1 in the text treatment and 19.1 in the video treatment). Moreover, non-mothers were also convinced that parents should rely less on grandparents for child care (from almost $20 \%$ of favorable women to only $11 \%)$.

These results may seem puzzling: why are non-mothers willing to use more (and pay more for) formal child care, if they then intend to work less, and thus to stay more at home? To address this issue, we divide our sample of nonmothers according to their education level. The existing literature (Carneiro et al. 2007; Monstad et al.2008; Guryan et al., 2008) shows that several female decisions, such as labor supply, child care, time of fertility, and even breastfeeding, differ across education attainments. These differences may be due to monetary incentives - as more educated earn on average higher wages, to different informational set - as educated women tend to be more informed, or even to different identity (see Akerlof and Kronton, 2000) - since low educated women may perceive themselves more as provider of maternal care, as opposed to more educated women who may identify themselves as both career oriented women and mothers. In the remaining of this section, we exploit this difference in education to further examine our experimental results. We will return to the possible channels proxied by education in the theoretical discussion at section 4.

Table 1 (columns 2 and 3) displays the average observed characteristics of 
our two sub-samples: low and high educated non-mothers, which corresponds to non-college and college graduate non-mothers. Some differences emerge. For instance, high educated women are more likely to be employed, and to read the newspaper; they are more left leaning and more religious.

Table 5 shows a stark difference in the response to our treatments between low and high educated non-mothers. Low educated non-mothers largely reduced their working intentions, both on the intensive (from $88.2 \%$ of women willing to work to around $76 \%$ ) and on the extensive margin (from 21.8 hours per week to around 17 hours), although they did not modify their formal child care decision. On the contrary, high educated non-mothers strongly increase their potential use of formal child care facilities (from $50 \%$ of potential users to $72.3 \%$ with the text treatment and $61.4 \%$ with the video), and their willingness to pay (by euro 50 ), whereas no significant effect emerged on the labor supply. The preferred amount of care by grandparents dropped for both types of non-mothers.

Since low and high educated non-mothers differ along some dimensions (see table 1), we run separate regressions, in which we control for individual characteristics, such as age, work status, being in a couple, reading and watching news, religiosity, political ideology, home ownership, residing in Southern Italy. We estimate the following equation for each education group:

$$
y_{q}=T^{\prime} \eta_{q}+X^{\prime} \kappa_{q}+\varepsilon_{q}
$$

where $y_{q}$ is the outcome of interest, and $q$ defines the outcome: use of formal childcare, willingness to pay, desired work status, desired hours of work, grandparents should look after grandchildren; $T$ is a vector of dummy variables which indicates the treatment (text, video, versus no information); $X$ is a vector of personal characteristics; $\varepsilon$ is a random error which follows a normal distribution for continuous outcomes (willingness to pay, desired hours of work) and 
a logistic cumulative distribution for binary outcomes (use of formal childcare, desired work status, grandparents should look after grandchildren); $\eta$ and $\kappa$ are the parameters to be estimated.

These estimates, reported at table 6 , confirm our previous results. Our treatments persuaded high - but not low - educated non-mothers to use more child care, and the difference across education groups is strongly significant. However, the treatments induce low - but not high - educated non-mothers to reduce their intention to work - on both margins, and this difference is again significant (for the text treatment). Using these additional controls, the effect of the treatments on the preferred grandparents use becomes more significant for both educational groups.

Although the responses to our treatments differ across education groups, it is important to emphasize that their perceptions about the message received in the treatments is similar. Table 7 shows that an overwhelming majority of both low and high educated non-mothers found the text and the video messages to be credible. These two education groups gave almost identical evaluation on how much they like the text (7.2 and 7.3 out of 10) and the video (7.8 and 7.6 out of 10). The only significant difference (at $10 \%$ level) emerged in their awareness of the information provided. More high educated (31.7\%) than low educated (20.7\%) non-mothers state that they were aware of the information released in the text treatment. This statistical difference does not instead emerge in the video treatment.

If low and high educated non-mothers share the same perceptions about our treatments, what explains the difference in their formal child care and labor supply intentions? Before turning, in the next section, to a theoretical analysis of the potential transmission mechanisms that lie behind our education variable, we want to rule out the possibility that education is systematically associated with other dimensions, such as political ideology, age or working status, which 
might explain the above results. Table 8 provides the results of the empirical specification which, besides the regressors at eq. 1, includes a full set of interactions of all observable characteristics (see table A1) with the treatment indicators (i.e., text and video). Despite being statistically more demanding, this specification confirms our previous results. Non-mothers responses to our treatments differ along education groups: high educated women increase their willingness to use formal child care; whereas low educated women reduce their intended labor supply. As a final robustness check, we run other empirical models in which non-mothers are partitioned into two groups along all other observable characteristics, but education. As reported in table 9, non-mothers responses to our treatment do not systematically differ along any other observable dimension, besides education.

\section{Theoretical Channels}

In this section, we provide a stylized theoretical framework ${ }^{15}$ to emphasize two possible mechanisms, which may lead low and high educated non-mothers to provide opposite responses to our treatment. Our first channel of interests is given by the differences in labor ability across women, which translates into different education attainments, and thus wages. Our second channel is the difference in their preference for maternal care. This different identity across women between a career oriented and a maternal type also affects their educational decisions.

\subsection{General features}

Women differ in their ability type, $e$, which represents the effort cost of becoming educated, and in their identity, which can be of career oriented or of maternal

\footnotetext{
${ }^{15}$ Models of female labour supply decisions and child care are numerous (see Apps and Rees, 2009). Earlier contributions such as Blau and Robbins (1988), Blau (1991) and Michalopoulos et al.(1992), Ribar (1995), have been recently enriched in dynamic models, which include also children skills' formation (Bernal, 2008).
} 
type (according to a preference parameter $\sigma$ ). In the first period of their life, women choose whether or not to get educated, which entails paying the related effort cost, $e$. Education yields a high wage, $w_{H}$, whereas uneducated working women receive a low wage, $w_{L}$. In the second period, women take their childcare and labor supply decisions.

All women care about consumption, $c$, child quality, $q$, and time spent with their child, $m$, according to the following utility function:

$$
U(c)+\beta U(q)+\sigma U(m)
$$

where $\beta$ and $\sigma$ represent respectively the relative preference for child quality and maternal time, and $U$ is a constant elasticity of substitution utility function $U(x)=x^{1-\rho} /(1-\rho)$. Women either have a career oriented identity, in which case $\sigma=0$, or a maternal identity, $\sigma>0$.

Women have one unit of time, to be allocated between labor supply, $n$, and maternal time, $m$. By supplying labor on the market, they obtain a wage, which can be low, $w_{L}$, or high, $w_{H}$, depending on their educational attainments. Women can count on additional resources, $y$, f.e., provided by their spouse. Child quality depends both on maternal time, $m$, and on time spent at formal child care, $k$, according to the following linear production function:

$$
q=Q(m, k)=\theta+A(\gamma m+\delta k)
$$

where $\theta$ measures the contribution to child quality of investments made later in life (after age three), $\gamma$ and $\delta$ represent respectively the productivity of maternal time and of the time at formal child care before age three, and $A$ is the total productivity of these early investments.

Besides maternal time and formal child care, children can be allocated to alternative informal care, $a$, such as grandparents or baby-sitters. This alternative care is assumed to be less productive for child quality, and for simplicity 
its productivity is set to 0 . The complete set of constraints faced by women in their labor and child care decisions is thus as follows:

$$
\begin{aligned}
1 & =n+m \\
1 & =k+a+m \\
n w+y & =c+p a+k h
\end{aligned}
$$

where the first equation represents the mother's time constraint, the second one is the child's time constraint, since young children have to be looked after at all time, and the last equation is the budget constraint. Notice that the total amount of resources is given by the female labor income, $n w$, and by the spouse additional income, $y$, and has to be divided between consumption, $c$, and resources spent on raising the child, consisting of the alternative care, $a$, which has a unitary cost, $p$, and of formal child care, $k$, which has a unitary cost, $h$.

\subsection{Women decisions}

In the second period, women decisions on child care and labor supply are defined by the following two first order conditions with respect to maternal time, $m$, and formal child care use, $k$ :

$$
\begin{aligned}
-\left(w_{i}-p\right) U^{\prime}(c)+\beta A \gamma U^{\prime}(q)+\sigma U^{\prime}(m) & \leq 0 \\
-(h-p) U^{\prime}(c)+\beta A \delta U^{\prime}(q) & \leq 0
\end{aligned}
$$

where $w_{i}=\left\{w_{L}, w_{H}\right\}$.

Consider first career oriented women, i.e., with $\sigma=0$. It is easy to see that, in this case, maternal care and formal child care are perfect substitutes. Women will only use the type of child care (maternal or formal), which provides a unit of child quality, $q$, at the lower cost. By assuming that

$$
\frac{w_{L}-p}{\gamma}<\frac{h-p}{\delta}<\frac{w_{H}-p}{\gamma}
$$


we thus have that low educated (and low wage) career oriented women will use only maternal care $\left(m^{*}>0, k^{*}=0\right)$, whereas high educated (and high wage) career oriented women will use only formal child care $\left(m^{*}=0, k^{*}>0\right)$. As a result, in the first period, only high ability women, characterized by a low effort cost of becoming educated, will choose to become educated.

For women with a maternal identity, i.e., with $\sigma>0$, it is clearly still the case that low educated (and low wage) women will use maternal care only $\left(m^{*}>0, k^{*}=0\right)$. In fact, maternal time is more cost effective in providing quality to the child, and moreover these women enjoy spending time with their child, as $\sigma>0$. Interestingly, maternal identity will lead even high educated (and high wage) women, for whom formal child care is more cost effective than maternal time in providing quality to the child, to spend some maternal time with their child. As in the case of career oriented types, in the first period, only high ability women, characterized by a low effort cost of becoming educated, will decide to become educated.

The next proposition summarizes these decisions.

Proposition 1 There exists a pair of effort cost thresholds $\left(\widetilde{e}_{C}, \widetilde{e}_{M}\right)$ such that: (i) high ability, career oriented $\left(e \leq \widetilde{e}_{C}, \sigma=0\right)$ and maternal type $\left(e \leq \widetilde{e}_{M}, \sigma>0\right)$ women become educated, and use formal child care, $k>0$ - the latter providing also some maternal time, $m>0$; and (ii) low ability, career oriented $\left(e>\widetilde{e}_{C}, \sigma=0\right)$ and maternal type $\left(e>\widetilde{e}_{M}, \sigma>0\right)$ women remain uneducated, provide maternal time, $m>0$, and do not use formal child care, $k=0$.

To be able to compare the effort cost thresholds for career oriented $\left(\widetilde{e}_{C}\right)$ and maternal type $\left(\widetilde{e}_{M}\right)$ women, we consider a logarithmic utility function $(\rho=1)$, and specify the quality production function at eq. 3 with $\theta=0$, i.e., no impact on quality of investments made after the age of three, and $\gamma=\delta$, so that the assumption at eq. 9 becomes $w_{L}<h<w_{H}$. Even when women with maternal 
identity display small preference for maternal care $(\sigma \rightarrow 0)$, and low wages are sufficiently large $\left(w_{L}>p+1\right)$, the effort cost threshold is lower among career women, $\widetilde{e}_{C}<\widetilde{e}_{M}$. In other words, women with intermediate ability types, $\widetilde{e}_{C}<e<\widetilde{e}_{M}$, will choose to become educated if they are career oriented, but not if they are of maternal type.

\subsection{The Effects of Information}

How does the release of information on the importance of early life education (before age three) for the future cognitive ability of a child, and in particular on the positive role played by formal child care, affect females' labor and child care decisions? And does this effect depend on the previous educational choice? Our theoretical model allows to study the effect in the second period, i.e., when education decisions have already been taken, of (i) an unexpected increase in the importance of early life education in the production of child quality, corresponding to an increase in $A$, and (ii) an unexpected increase in the perceived productivity of formal child care in producing child quality, corresponding to an increase in $\delta$. The next proposition summarizes the results for a CES utility function, which features a moderate degree of the elasticity of substitution (f.e., logarithmic).

Proposition 2 Consider a CES utility function with $\rho \leq 1+\theta / A(\delta+\gamma)$. An unexpected increase in the second period of the productivity of early life education on child quality (higher A): (i) increases maternal care among low educated women; and (ii) increases formal child care among high educated women. An unexpected increase in the second period of the productivity of formal child care on child quality (higher $\delta$ ), such that the assumptions at eq.9 still hold: (i) has no effect on low educated women; and (ii) increases formal child care among high educated women. 
The above proposition suggests that - in line with our experimental results - women's response to the release of information on the importance of early life education and of formal child care differs according to their educational attainments. Low educated women increase maternal time and reduce their labor supply; while high educated women increase formal child care use. Note also that the results of the above proposition imply that - in line with our experimental results - both type of women reduce the use of alternative informal care $(a)$, such as grand-parents and baby-sitters. Our stylized theoretical model suggests that two different channels may be at work: maternal identity and/or wage differentials.

\section{Conclusions}

A recent literature has emphasized the role of information on the effects of maternal employment in influencing female labor force participation. We provide a test of the effects of information by designing a survey experiment that exposed a group of women to a text or video message on the future educational and working benefits for children who attended formal child care. Among non-mothers, who yet have to face this child care decision, our treatments have a puzzling effect: willingness to use formal child care increases, but desired work hours drop and fewer women desire to work. This average effect unveils important differences by education. High educated non-mothers react to our treatments by increasing their willingness to send their (future) child to formal care and to pay for it, while their labor supply intentions are unchanged. Quite on the contrary, low educated non-mothers do not modify their potential use of formal child care, but prefer to work fewer hours, and fewer low-educated non-mothers still want to work.

Why is education creating such a divide in the non-mothers intended behav- 
ior? Our empirical analysis shows that this difference in intended behavior is not driven by a different appreciation of the messages received in the treatment. In fact, low and high educated non-mothers share the same perceptions about these messages. A large majority (around 75\%) found the text and the video messages to be credible, and liked them (with a score of around 7.5 out of 10); although not many non-mothers $-20.7 \%$ of the low educated and $31.7 \%$ of the high-educated - self declared to have been aware about the information provided in the text. Moreover, our empirical analysis rules out other confounding effects, such political ideology, age, religiosity or marital status, which could have driven this difference.

To identify potential transmission channels that may explain why low and high educated non-mothers (intend to) act differently, we provide a simple theoretical framework, which links education to wages and maternal preferences. High ability types and career oriented women choose to become educated and, as a result, obtain a high wage. As our treatment increases the salience of the early life education and the role of formal child care, low wage women respond by increasing their role as care provider for their child and reduce labor supply. On the other hand, high wage women respond by increasing their intended child care use. Hence, both market based and preference based transmission channels are consistent with our experimental results.

The existence of a possible double transmission channel has important policy implications. Public policies about child care use should acknowledge that child care decisions by the mothers may depend on budgetary restrictions - as in the case of low wage mothers - but also on maternal identity. Some (low educated) mothers may choose to keep for themselves the role of main care provided for their children, even when family friendly institutions are available. 


\section{References}

[1] Akerlof, G. and Kranton,(2000) "Economics and Identity" Quarterly Journal of Economics 115(3): 715-753.

[2] Apps, P. \& R. Rees (2009): Public Economics and the Household. Cambridge University Press

[3] Avery et al. (2006)

[4] Avitabile, C. (2012) Does Information Improve the Health Behavior of Adults Targeted by a Conditional Transfer Program? Journal of Human Resources 47 (3): 785-825.

[5] Baker, M., J.Gruber and K. Milligan (2008) Universal Child Care, Maternal Labor Supply, and Family Well-Being. Journal of Political Economy, 116(4): 709-745.

[6] Baum, C. L. (2003) Does early maternal employment harm children? Journal of Labor Economics 21:409-448.

[7] Bernal, R. (2008). The effect of maternal employment and child care on children's cognitive development International Economic Review 49(4):11731209.

[8] Bernal, R., and M. Keane. (2011). Child care choices and children's cognitive achievement: the case of single mothers, Journal of Labor Economics 29(3): $459-512$.

[9] Bernal, R. and M. Keane (2010) Quasi-Structural Estimation of a Model of childcare Choices and Child Cognitive Ability Production. Journal of Econometrics 156(1): 164-189. 
[10] Blau, D. (1991) (ed) The Economics of Child Care, Russell Stage Foundation

[11] Blau, D. and Robbins, P. (1988) childcare Costs and Family Labor Supply. The Review of Economics and Statistics , 70(3): 374-381.

[12] Bostrom (1983)

[13] Brilli Y., Del Boca D., Pronzato C. (2011) Exploring the Impacts of Public Childcare on Mothers and Children in Italy: Does Rationing Play a Role? IZA DP 5918.

[14] Carneiro, P. and Heckman, J. J. (2003), Human Capital Policy, in J.Heckman, A. B. Krueger, and Friedman, B. M. (Eds.), Inequality in America: What Role for Human Capital Policies?, Cambridge, MA: MIT Press, 77-239.

[15] Carneiro P., Meghir C., and Parey M. (2007). Maternal Education, Home Environments and Child Development, IZA Discussion paper 3072

[16] Casarico, A. and Profeta, P. (2010) Donne in attesa, Egea.

[17] Cascio, E., 2009, Maternal Labor Supply and the Introduction of Kindergartens into American Public Schools, Journal of Juman Resources

[18] Cochran, J. and Chamlin, M. (2005) Can information change public opinion? Another test of the Marshall hypotheses, Journal of Criminal Justice 33: $573-584$.

[19] Cunha, F., Heckman, J. and Schennach, S. (2010) Estimating the Technology of Cognitive and Noncognitive Skill Formation, Econometrica, 78(3): 883-931. 
[20] Del Boca, D. (2002) The Effect of Childcare and Part Time Opportunities on Participation and Fertility Decisions in Italy, Journal of Population Economics 15(3): 549-573.

[21] Del Boca, D., Pasqua, S. and Pronzato, C. (2009) Motherhood and Market Work Decisions in Institutional Context: a European Perspective Oxford Economic Papers.

[22] Del Boca, D., Mencarini, L. and Pasqua, S. (2012) Valorizzare le donne conviene. Il Mulino.

[23] Della Vigna, S. and Gantzkow (2010) Persuasion: Empirical Evidence, with Matthew Gentzkow, Annual Review of Economics 2.

[24] Dupas, 2009

[25] Dustmann C. and Schonberg U., 2012, Expansions in Maternity Leave Coverage and Children's Long-Term Outcomes, American Economic Journal: Applied Economics, 4(3): 190-224.

[26] Felfe C. and Lalive R. (2010) How Does Early Childcare Affect Child Development? Learning from the Children of German Unification, CESifo Area Conference on Economics of Education, Center for Economics Studies, mimeo.

[27] Fernàndez, R., Fogli, A. and Olivetti, C. (2004) "Mothers and Sons: Preference Formation and Female Labor Force Dynamics" Quarterly Journal of Economics 119(4): 1249-1299.

[28] Fernàndez, R. (2007) Women, Work and Culture, Journal of the European Economic Association 5(2-3): 305-332.

[29] Fitzpatrick, M. Preschoolers enrolled and mothers at work? The effects of universal pre-kindergarten, mimeo, Stanford University 
[30] Fogli, A. and Veldkamp, L. (2011) Nature or Nurture? Learning and the Geography of Female Labor Force Participation, Econometrica, 79(4): 1103-1138, 07.

[31] Gelbach, J. 2002. Public schooling for young children and maternal labor supply, American Economic Review 92, no. 1:307-22.

[32] Gneezy U., Niederle M., Rustichini A., 2003, Performance in Competitive Environments: Gender Differences, Quarterly Journal of Economics, CXVIII, August, 1049 - 1074.

[33] Guryan J., Hurst E. and Kearney M. (2008). Parental education and parental time with children, Journal of Economic Perspectives, 22(3): 2346.

[34] Havnes T. and Mogstad M. (2011) No Child Left Behind. Universal Childcare and Children's Long-Run Outcomes, American Economic Journal: Economic Policy, 3, 97-129.

[35] Kalmijn, M. and Poortman, A. His or Her Divorce? The Gendered Nature of Divorce and its Determinants Eur Sociol Rev (April 2006) 22(2): 201-214

[36] Lefebvre and Merrigan, 2008. childcare Policy and the Labor Supply of Mothers with Young Children: A Natural Experiment from Canada, Journal of Labor Economics 6(3), 519-548.

[37] Michalopoulos, C. Robins, P. and Garfinkel, I. A Structural Model of Labor Supply and Child Care Demand. The Journal of Human Resources Vol. 27 (1): 166-203. 
[38] Monstad K., Propper C. and Salvanes K. (2008). Education and Fertility: Evidence from a Natural Experiment, The Scandinavian Journal of Economics, 110, 4: 827-852

[39] Pfau-Effinger, B. (2000) "Conclusion: Gender Culture, Gender Arrangements and Social Change in the European Context" in: S. Duncan and B. Pfau-Effinger (eds.), Gender, Economy and Culture in the European Union, Routledge

[40] Piketty, T., 2005. L'impact de l'Allocation parentale d'éducation sur l'activité féminine et la fécondité en France, 1982-2002. In Lefebvre, C. and Filhon, A. ,Histoires de familles, histoires familiales, Les Cahiers de l'INED, no. 156:79-109.

[41] Poortman, A. Women's Work and Divorce: A Matter of Anticipation? A Research Note, Eur Sociol Rev (July 2005) 21(3): 301-309.

[42] Ribar, D. C., 1995, A structural model of child care and the labor supply of married women. Journal of Labor Economics 13(3): pp. 558-97.

[43] Ruhm, C.J. (2004) Parental employment and child cognitive development. Journal of Human Resources 39:155-192.

[44] Schone, Pal. 2004. Labour supply effects of a cash-for-care subsidy. Journal of Population Economics 17, no. 4:703-27. 
[45] Suarez, M. 2013. Working mothers' decisions on childcare: the case of Spain, forthcoming Review of Economics of the Household. 


\section{Appendix}

\section{Proof of Proposition 1}

First, consider career oriented women, i.e., $\sigma=0$. It is straightforward to see that - in the second period - given the assumption at eq. 9, and the first order conditions at eq. 7 and 8 , with $\sigma=0$, either maternal time or formal child care are used, but not both. For low wage (uneducated) women, since $\frac{w_{L}-p}{\gamma}<\frac{h-p}{\delta}$, no formal child care is used, $k=0$; simple algebra shows that maternal time is

$$
m=\frac{w_{L}-p+y-\theta \Lambda}{w_{L}-p+A \Lambda \gamma}>0
$$

, where $\Lambda=\left(\frac{w_{L}-p}{A \beta \gamma}\right)^{1 / \rho}$. The associated utility is $V\left(c, q, m ; w_{L}, \sigma=0\right)$. For high wage (educated) women, since $\frac{h-p}{\delta}<\frac{w_{H}-p}{\gamma}$, no maternal time is used, $m=0$, and simple algebra shows that formal child care is

$$
k=\frac{w_{H}-p+y-\theta \Psi}{h-p+A \Psi \delta}>0
$$

, where $\Psi=\left(\frac{h-p}{A \beta \delta}\right)^{1 / \rho}$. The associated utility is $V\left(c, q, m ; w_{H}, \sigma=0\right)$. For a given women type, in particular $\sigma=0$, the utility is increasing in the wage. Thus, there exists an effort cost threshold $\widetilde{e}_{C}$, such that $V\left(c, q, m ; w_{H}, \sigma=0\right)-$ $\widetilde{e}_{C}=V\left(c, q, m ; w_{L}, \sigma=0\right)$. Hence, for $e \leq \widetilde{e}_{C}$, in the first period, career oriented women choose to become educated, whereas for $e>\widetilde{e}_{C}$ they do not.

Now, consider maternal type women, i.e., $\sigma>0$. It is straightforward to see that - in the second period - given the first order conditions at eq. 7 and 8 , with $\sigma>0$, low wage (uneducated) women use no formal child care, $k=0$, since $\frac{w_{L}-p}{\gamma}<\frac{h-p}{\delta}$. Their use of maternal care is implicitly defined by the first order condition at eq. 7 , which holds with equality, with $k=0$ and $w_{i}=w_{L}$. Define the associated utility as $V\left(c, q, m ; w_{L}, \sigma>0\right)$. For high wage (educated) women, maternal time is used, $m>0$, as the first order condition at eq. 7 goes to infinity for $m \rightarrow 0$. However, since $\frac{h-p}{\delta}<\frac{w_{H}-p}{\gamma}$, formal child care could 
also be used, so that also the first order condition at eq. 8 could also hold with equality. If both eq. 7 and 8 hold with equality, we can obtain the following Euler equation:

$$
-A\left[\frac{w_{H}-p}{h-p} \delta-\gamma\right] U^{\prime}(q)+\sigma U^{\prime}(m)=0
$$

Taking total differential on the above equation, it is easy to see that there exists a positive relation between $m$ and $k$. Using the first order condition at eq. 8 and the budget constraints at eq. 4, 5, and 6 , we can obtain another, yet negative, equilibrium relation between $m$ and $k$. If the curves $k(m)$ defined at equations 12 and 8 cross, this represents the optimal decision $(m>0, k>0)$ by the high wage maternal type women. The associated utility is $V\left(c, q, m ; w_{H}, \sigma>0\right)$. For a given women type, this time $\sigma>0$, the utility is increasing in the wage. Thus, there exists an effort cost threshold $\widetilde{e}_{M}$, such that $V\left(c, q, m ; w_{H}, \sigma>0\right)-\widetilde{e}_{M}=$ $V\left(c, q, m ; w_{L}, \sigma>0\right)$. Hence, for $e \leq \widetilde{e}_{M}$, in the first period, career oriented women choose to become educated, whereas for $e>\widetilde{e}_{M}$ they do not. qed.

\section{Proof of Proposition 2}

(i) We begin with an unexpected increase in the productivity of early life education on child quality (higher $A$ ) in the second period.

Consider career oriented women, i.e., $\sigma=0$. Among low educated, who choose $k=0$ and $m>0$, it is straightforward to see from eq. 10 that $\partial m / \partial A>$ 0 , if $\rho<1+\theta / A \gamma m$. Among high educated, who choose $k>0$ and $m=0$, it is straightforward to see from eq. 11 that $\partial k / \partial A>0$, if $\rho<1+\theta / A \delta k$.

Consider now maternal type women, i.e., $\sigma>0$. Among low educated, who choose $k=0$ and $m>0$, it is straightforward to see, by applying the total differential to eq. 7 holding with equality, that $\partial m / \partial A>0$, if $\rho<1+\theta / A \gamma m$. To examine the effect of an increase in $A$ on the high educated, who choose $k>0$ and $m>0$, we need to consider how the effect on the curves $k(m)$ defined at equations 12 and 8 . By total differentiating equations 12 and 8 with respect 
to $k$ and $A$, it is easy to see that both curves $k(m)$ shift upward after an increase in $A$, if $\rho<1+\theta / A(\gamma m+\delta k)$. Hence, an increase in $A$ induces an increase in $k$, whereas the effect on $m$ is indeterminate.

(ii) We now turn to an unexpected increase in the productivity of formal child care on child quality (higher $\delta$ ) in the second period, which does not modify the assumptions at eq. 9.

Consider career oriented women, i.e., $\sigma=0$. Among low educated, who choose $k=0$ and $m>0$, a change in $\delta$ has no effect. Among high educated, who choose $k>0$ and $m=0$, it is straightforward to see from eq. 11 that $\partial k / \partial \delta>0$, if $\rho<1+\theta / A \delta k$.

Consider now maternal type women, i.e., $\sigma>0$. Among low educated, who choose $k=0$ and $m>0$, a change in $\delta$ has no effect. To examine the effect of an increase in $\delta$ on the high educated, who choose $k>0$ and $m>0$, we need to consider how the effect on the curves $k(m)$ defined at equations 12 and 8. By total differentiating equations 12 and 8 with respect to $k$ and $\delta$, it is easy to see that both curves $k(m)$ shift upward after an increase in $\delta$, if $\rho<1+(\theta+A \gamma m) / A \delta k$. Hence, an increase in $A$ induces an increase in $k$, whereas the effect on $m$ is indeterminate. qed 
Tables

Table 1: Descriptive statistics

\begin{tabular}{lccc}
\hline Variable & All women & $\begin{array}{c}\text { Low educated } \\
\text { non-mothers }\end{array}$ & $\begin{array}{c}\text { High educated } \\
\text { non-mothers }\end{array}$ \\
\hline Mother (\%) & 53.7 & - & - \\
Tertiary education (\%) & 38.9 & 0.0 & 100.0 \\
Age & 31.7 & 28.7 & 29.7 \\
Employed (\%) & 61.5 & 50.3 & 66.0 \\
In a couple (\%) & 67.0 & 33.9 & 38.8 \\
Watches news (\%) & 58.7 & 57.8 & 56.7 \\
Reads news (\%) & 63.7 & 59.1 & 69.2 \\
Religious (\%) & 35.4 & 26.0 & 35.9 \\
Political ideology: left (\%) & 44.8 & 42.7 & 58.3 \\
Political ideology: right (\%) & 47.2 & 50.5 & 37.2 \\
Political ideology: missing (\%) & 8.1 & 6.8 & 4.5 \\
Home owner (\%) & 77.4 & 76.8 & 78.8 \\
South (\%) & 33.3 & 37.0 & 34.9 \\
Observations & 1,503 & 384 & 312 \\
\hline
\end{tabular}

Table 2: Randomization of the treatments (all women)

\begin{tabular}{lccc}
\hline & Text & Video & No treatment \\
\hline Mother (\%) & 53.0 & 53.8 & 54.3 \\
Tertiary education (\%) & 40.0 & 37.2 & 39.5 \\
Age & 31.5 & 31.6 & 31.9 \\
Employed (\%) & 61.4 & $58.4^{* *}$ & 64.7 \\
In a couple (\%) & 66.3 & 67.8 & 66.9 \\
Watches news (\%) & 58.2 & 59.2 & 58.7 \\
Reads news (\%) & 64.5 & 65.2 & 61.5 \\
Religious (\%) & 36.7 & 35.2 & 34.3 \\
Political ideology: left (\%) & $41.2^{* *}$ & 44.2 & 48.9 \\
Political ideology: right (\%) & 50.2 & 46.0 & 45.3 \\
Political ideology: missing (\%) & $8.6^{*}$ & $9.8^{* *}$ & 5.8 \\
Home owner (\%) & 78.7 & 77.6 & 75.8 \\
South (\%) & 30.7 & 35.4 & 33.9 \\
Observations & 502 & 500 & 501 \\
\hline
\end{tabular}

Notes: average characteristics of women treated by the text, treated by the video, and untreated. Significant differences of "text" and "video" with respect to "no treatment": *** at $1 \%$ level, $* *$ at $5 \%$ level, * at $10 \%$ level. 
Table 3: Randomization of the treatments (non-mothers)

\begin{tabular}{lccc}
\hline & Text & Video & No treatment \\
\hline Tertiary education (\%) & 42.8 & 43.7 & 48.0 \\
Age & 28.9 & 29.1 & 29.6 \\
Employed (\%) & 59.7 & $51.9 *$ & 60.3 \\
In a couple (\%) & 35.6 & 36.4 & 36.2 \\
Watches news (\%) & 58.5 & 55.8 & 57.6 \\
Reads news (\%) & 64.8 & 63.6 & 62.4 \\
Religious (\%) & 30.9 & 29.0 & 31.4 \\
Political ideology: left (\%) & 46.2 & 50.2 & 52.8 \\
Political ideology: right (\%) & 47.9 & 43.7 & 41.9 \\
Political ideology: missing (\%) & 5.9 & 6.1 & 5.2 \\
Home owner (\%) & 81.4 & 76.2 & 75.5 \\
South (\%) & 33.9 & 39.0 & 35.4 \\
Observations & 236 & 231 & 229 \\
\hline
\end{tabular}

Notes: average characteristics of women treated by the text, treated by the video, and untreated. Significant differences of "text" and "video" with respect to "no treatment": *** at $1 \%$ level, ** at $5 \%$ level, * at $10 \%$ level.

Table 4: Average treatment effects

\begin{tabular}{|c|c|c|c|c|c|}
\hline Treatment & $\begin{array}{l}\text { Would send the } \\
\text { child to formal } \\
\text { childcare } \\
(\%)\end{array}$ & $\begin{array}{l}\text { Willingness to } \\
\text { pay for formal } \\
\text { childcare } \\
(€)\end{array}$ & $\begin{array}{c}\text { Desired work } \\
\text { status } \\
(\%) \\
\end{array}$ & $\begin{array}{l}\text { Desired hours } \\
\text { of work }\end{array}$ & $\begin{array}{c}\text { Grandparents } \\
\text { should look } \\
\text { after } \\
\text { grandchildren } \\
(\%)\end{array}$ \\
\hline \multicolumn{6}{|l|}{ All women } \\
\hline Text & & 324 & 78.5 & 18.5 & $13.9 *$ \\
\hline Video & & 328 & 78.4 & $17.1^{* *}$ & 18.0 \\
\hline No treatment & & 315 & 81.8 & 19.2 & 18.0 \\
\hline Observations & 1,503 & 1,503 & 1,503 & 1,503 & 1,503 \\
\hline \multicolumn{6}{|l|}{ Non-mothers } \\
\hline Text & $58.5 * * *$ & $361^{*}$ & $81.4^{* *}$ & $20.1^{* *}$ & $11.0^{* *}$ \\
\hline Video & 47.2 & 337 & $81.8^{* *}$ & $19.1 * * *$ & 14.3 \\
\hline No treatment & 44.1 & 328 & 89.1 & 23.0 & 19.7 \\
\hline Observations & 696 & 696 & 696 & 696 & 696 \\
\hline
\end{tabular}

Notes: average outcomes of women treated by the text, treated by the video, and untreated. Significant differences of "text" and "video" with respect to "no treatment": ${ }^{* * *}$ at $1 \%$ level, ${ }^{* *}$ at $5 \%$ level, ${ }^{*}$ at $10 \%$ level. 


\begin{tabular}{|c|c|c|c|c|c|}
\hline & $\begin{array}{l}\text { Would send the } \\
\text { child to formal } \\
\text { childcare } \\
\text { (\%) }\end{array}$ & $\begin{array}{l}\text { Willingness to } \\
\text { pay for formal } \\
\text { childcare } \\
(€)\end{array}$ & $\begin{array}{l}\text { Desired work } \\
\text { status } \\
\text { (\%) }\end{array}$ & $\begin{array}{l}\text { Desired hours } \\
\text { of work }\end{array}$ & $\begin{array}{l}\text { Grandparents } \\
\text { should look } \\
\text { after } \\
\text { grandchildren } \\
\text { (\%) }\end{array}$ \\
\hline \multicolumn{6}{|c|}{$\begin{array}{l}\text { Low educated women } \\
\text { ( } 384 \text { observations) }\end{array}$} \\
\hline Text & 48.1 & 336 & $75.6 * *$ & $17.6^{* *}$ & 14.8 \\
\hline Video & 36.2 & 319 & $76.9 * *$ & $17.3^{* * *}$ & 16.9 \\
\hline \multicolumn{6}{|c|}{$\begin{array}{l}\text { High educated women } \\
\text { ( } 312 \text { observations) }\end{array}$} \\
\hline Text & $72.3 * * *$ & $395^{*}$ & 89.1 & 23.4 & $5.9^{* *}$ \\
\hline Video & $61.4^{*}$ & 359 & 88.1 & 21.5 & 10.9 \\
\hline No treatment & 50.0 & 345 & 90.0 & 24.3 & 16.4 \\
\hline
\end{tabular}

Notes: average outcomes of women treated by the text, treated by the video, and untreated. Significant differences of "text" and "video" with respect to "no treatment": ${ }^{* * *}$ at $1 \%$ level, ${ }^{* *}$ at $5 \%$ level, ${ }^{*}$ at $10 \%$ level.

Table 6: Treatment effects by level of education (non-mothers)

\begin{tabular}{|c|c|c|c|c|c|}
\hline & $\begin{array}{l}\text { Would send the } \\
\text { child to formal } \\
\text { childcare } \\
(\%)\end{array}$ & $\begin{array}{l}\text { Willingness to } \\
\text { pay for formal } \\
\text { childcare } \\
(€)\end{array}$ & $\begin{array}{l}\text { Desired work } \\
\text { status } \\
(\%)\end{array}$ & $\begin{array}{l}\text { Desired hours } \\
\text { of work }\end{array}$ & $\begin{array}{l}\text { Grandparents } \\
\text { should look } \\
\text { after } \\
\text { grandchildren } \\
\text { (\%) }\end{array}$ \\
\hline \multicolumn{6}{|c|}{$\begin{array}{l}\text { Effects for } \\
\text { high educated women }\end{array}$} \\
\hline Text & $\begin{array}{c}1.13^{* * *} \\
(3.64)\end{array}$ & $\begin{array}{l}58^{* *} \\
(2.15)\end{array}$ & $\begin{array}{l}-0.06 \\
(0.13)\end{array}$ & $\begin{array}{c}-0.4 \\
(0.20)\end{array}$ & $\begin{array}{c}-1.40^{* * *} \\
(2.69)\end{array}$ \\
\hline Video & $\begin{array}{l}0.68^{* *} \\
(2.28)\end{array}$ & $\begin{array}{c}29 \\
(1.09)\end{array}$ & $\begin{array}{l}-0.01 \\
(0.01)\end{array}$ & $\begin{array}{c}-2.4 \\
(1.32)\end{array}$ & $\begin{array}{l}-0.67 \\
(1.49)\end{array}$ \\
\hline \multicolumn{6}{|c|}{$\begin{array}{l}\text { Effects for } \\
\text { low educated women }\end{array}$} \\
\hline Text & $\begin{array}{c}0.35 \\
(1.32)\end{array}$ & $\begin{array}{c}15 \\
(0.62)\end{array}$ & $\begin{array}{c}-1.13^{* * *} \\
(3.05)\end{array}$ & $\begin{array}{l}-4.8^{* * *} \\
(2.95)\end{array}$ & $\begin{array}{l}-0.57^{*} \\
(1.67)\end{array}$ \\
\hline Video & $\begin{array}{l}-0.22 \\
(0.81)\end{array}$ & $\begin{array}{c}4 \\
(0.18)\end{array}$ & $\begin{array}{c}-0.97 * * * \\
(2.59)\end{array}$ & $\begin{array}{c}-4.9 * * * \\
(2.97)\end{array}$ & $\begin{array}{l}-0.37 \\
(1.10)\end{array}$ \\
\hline \multicolumn{6}{|c|}{$\begin{array}{l}\text { Testing different effects } \\
\text { by level of education }\end{array}$} \\
\hline Text & $1.92 * *$ & 1.19 & $1.77^{*}$ & $1.82^{*}$ & 1.34 \\
\hline Video & $2.23 * *$ & 0.68 & 1.61 & 1.02 & 0.54 \\
\hline Observations & 696 & 696 & 696 & 696 & 696 \\
\hline
\end{tabular}

Notes: the top part of the table reports the effects (and the t-ratios in brackets) of text and video on the outcome variables estimated separately for high and low educated women, through linear regressions for continuous outcomes and logistic regressions for binary outcomes; controlling for age, work, being in a couple, reading/watching news, religiosity, political ideology, home ownership, South; significant effects of video and text: ${ }^{* * *}$ at $1 \%$ level, ${ }^{* *}$ at $5 \%$ level, ${ }^{*}$ at $10 \%$ level. The bottom part of the table reports the t-ratios related to the difference between "high educated" and "low educated" effects, significant differences: $* * *$ at $1 \%$ level, ${ }^{* *}$ at $5 \%$ level, $*$ at $10 \%$ level. 
Table 7: Appreciation of the information (non-mothers)

\begin{tabular}{lcccc}
\hline & $\begin{array}{c}\text { Aware of the } \\
\text { information provided } \\
(\%)\end{array}$ & $\begin{array}{c}\text { The message was } \\
\text { credible } \\
(\%)\end{array}$ & $\begin{array}{c}\text { How much she liked } \\
\text { the text / video } \\
\text { (from 1 to 10) }\end{array}$ & Observations \\
\hline Text & $31.7^{*}$ & 77.2 & 7.3 & 101 \\
High educated women & 20.7 & 71.1 & 7.2 & 135 \\
Low educated women & 28.7 & & 7.8 & 101 \\
Video & 24.6 & 78.2 & 7.6 & 130 \\
High educated women & & 78.5 & 467 \\
Low educated women & & & 4.6 \\
Total observations & & & & \\
\hline
\end{tabular}

Notes: appreciation of the information by women treated by the text and treated by the video. Significant differences of "text" with respect to "video": *** at $1 \%$ level, ${ }^{* *}$ at $5 \%$ level, * at $10 \%$ level.

Table 8: Treatment effects with interactions (non-mothers)

(treatment effects allowed to be different for women with different characteristics)

\begin{tabular}{|c|c|c|c|c|c|}
\hline & $\begin{array}{l}\text { Would send the } \\
\text { child to formal } \\
\text { childcare } \\
(\%)\end{array}$ & $\begin{array}{l}\text { Willingness to } \\
\text { pay for formal } \\
\text { childcare } \\
(€)\end{array}$ & $\begin{array}{l}\text { Desired work } \\
\text { status } \\
(\%)\end{array}$ & $\begin{array}{l}\text { Desired hours } \\
\text { of work }\end{array}$ & $\begin{array}{c}\text { Grandparents } \\
\text { should look } \\
\text { after } \\
\text { grandchildren } \\
\text { (\%) }\end{array}$ \\
\hline \multicolumn{6}{|c|}{$\begin{array}{l}\text { Effects for } \\
\text { high educated women }\end{array}$} \\
\hline Text & $\begin{array}{c}1.12^{* * *} \\
(3.49)\end{array}$ & $\begin{array}{l}63^{* *} \\
(2.24)\end{array}$ & $\begin{array}{c}0.15 \\
(0.30)\end{array}$ & $\begin{array}{c}-0.4 \\
(0.21)\end{array}$ & $\begin{array}{l}-1.29 * * \\
(2.33)\end{array}$ \\
\hline Video & $\begin{array}{l}0.64^{* *} \\
(2.12)\end{array}$ & $\begin{array}{c}12 \\
(0.44)\end{array}$ & $\begin{array}{l}-0.23 \\
(0.48)\end{array}$ & $\begin{array}{l}-3.1^{*} \\
(1.70)\end{array}$ & $\begin{array}{l}-0.69 \\
(1.46)\end{array}$ \\
\hline \multicolumn{6}{|c|}{$\begin{array}{l}\text { Effects for } \\
\text { low educated women }\end{array}$} \\
\hline Text & $\begin{array}{c}0.36 \\
(1.31)\end{array}$ & $\begin{array}{c}12 \\
(0.48)\end{array}$ & $\begin{array}{c}-1.14^{* * * *} \\
(2.83)\end{array}$ & $\begin{array}{c}-4.6 * * * \\
(2.80)\end{array}$ & $\begin{array}{l}-0.57 \\
(1.47)\end{array}$ \\
\hline Video & $\begin{array}{l}-0.20 \\
(0.73) \\
\end{array}$ & $\begin{array}{c}10 \\
(0.40) \\
\end{array}$ & $\begin{array}{c}-0.93^{* *} \\
(2.25) \\
\end{array}$ & $\begin{array}{l}-4.4^{* * *} \\
(2.65) \\
\end{array}$ & $\begin{array}{l}-0.20 \\
(0.56) \\
\end{array}$ \\
\hline \multicolumn{6}{|c|}{$\begin{array}{l}\text { Testing different effects } \\
\text { by level of education }\end{array}$} \\
\hline Text & $1.77^{*}$ & 1.32 & $2.04 * *$ & $1.65^{*}$ & 1.11 \\
\hline Video & $1.99 * *$ & 0.06 & 1.12 & 0.50 & 0.83 \\
\hline Observations & 696 & 696 & 696 & 696 & 696 \\
\hline
\end{tabular}

Notes: the top part of the table reports the effects (and the t-ratios in brackets) of text and video on the outcome variables, estimated through linear regressions for continuous outcomes and logistic regressions for binary outcomes; controlling for age, work, being in a couple, reading/watching news, religiosity, political ideaology, home ownership, South and their interactions with text and video; significant effects of video and text: ${ }^{* * *}$ at $1 \%$ level, ${ }^{* *}$ at $5 \%$ level, ${ }^{*}$ at $10 \%$ level. The bottom part of the table reports the t-ratios related to the difference between "high educated" and "low educated" effects, significant differences: $* * *$ at $1 \%$ level, ${ }^{* *}$ at $5 \%$ level, $*$ at $10 \%$ level. 


\begin{tabular}{|c|c|c|c|c|c|}
\hline & $\begin{array}{l}\text { Would send the } \\
\text { child to formal } \\
\text { childcare } \\
(\%)\end{array}$ & $\begin{array}{l}\text { Willingness to } \\
\text { pay for formal } \\
\text { childcare } \\
(€)\end{array}$ & $\begin{array}{l}\text { Desired work } \\
\text { status } \\
(\%)\end{array}$ & $\begin{array}{l}\text { Desired hours } \\
\text { of work }\end{array}$ & $\begin{array}{l}\text { Grandparents } \\
\text { should look } \\
\text { after } \\
\text { grandchildren } \\
(\%)\end{array}$ \\
\hline \multicolumn{6}{|c|}{ Younger than 31} \\
\hline Text & 0.45 & 0.14 & 0.11 & 0.24 & 0.26 \\
\hline Video & 0.99 & 0.39 & 0.17 & 0.13 & 0.16 \\
\hline \multicolumn{6}{|l|}{ Work } \\
\hline Text & 0.39 & 1.41 & 0.37 & 1.03 & 0.02 \\
\hline Video & 0.31 & 0.27 & 0.44 & 1.05 & 0.92 \\
\hline \multicolumn{6}{|c|}{ In a couple } \\
\hline Text & 0.08 & 0.11 & 0.44 & 0.22 & 1.21 \\
\hline Video & 0.84 & 0.03 & 0.23 & 0.88 & 0.73 \\
\hline \multicolumn{6}{|c|}{ Watches news } \\
\hline Text & 0.64 & 0.26 & 0.32 & 0.01 & $2.01 * *$ \\
\hline Video & 1.06 & 0.44 & 0.34 & 0.35 & 0.91 \\
\hline \multicolumn{6}{|c|}{ Reads news } \\
\hline Text & $1.68^{*}$ & 0.88 & 0.32 & 1.48 & 0.94 \\
\hline Video & 0.73 & 0.43 & 1.49 & 1.47 & 0.79 \\
\hline \multicolumn{6}{|c|}{ Religious } \\
\hline Text & 0.78 & 0.91 & 0.36 & 0.75 & 0.12 \\
\hline Video & 0.20 & 1.53 & $2.91 * * *$ & 0.63 & 1.10 \\
\hline \multicolumn{6}{|l|}{ Leftist } \\
\hline Text & 1.16 & 0.11 & 0.35 & 0.14 & 1.25 \\
\hline Video & 0.71 & 1.03 & 0.29 & 0.32 & 1.15 \\
\hline \multicolumn{6}{|c|}{ Home owner } \\
\hline Text & 0.14 & 0.23 & 0.15 & 0.00 & 0.83 \\
\hline Video & 0.37 & 0.67 & 0.29 & 0.52 & 0.50 \\
\hline \multicolumn{6}{|c|}{ South of Italy } \\
\hline Text & 0.80 & 0.27 & 0.85 & 1.34 & $1.68^{*}$ \\
\hline Video & 0.88 & 1.38 & 0.78 & 0.65 & 0.04 \\
\hline
\end{tabular}

Notes: the table reports the t-ratios related to the difference of the effects of text and video between women belonging to one group (for example: younger, 30 years or less) rather than the other group (older, older than 31 ); significant differences: $* * *$ at $1 \%$ level, $* *$ at $5 \%$ level, $*$ at $10 \%$ level. 


\section{Appendix}

\section{Table A1: Variables description}

\begin{tabular}{|c|c|}
\hline $\begin{array}{l}\text { Would send the child to } \\
\text { formal childcare }\end{array}$ & 1: Yes; 0: No, doesn't know \\
\hline $\begin{array}{l}\text { Willingness to pay for } \\
\text { formal childcare }\end{array}$ & Amount in $€$ \\
\hline Desired work status & 1: Work; 0: No work \\
\hline Desired hours of work & From 0 to 99 \\
\hline $\begin{array}{l}\text { Grandparents should look } \\
\text { after grandchildren }\end{array}$ & $\begin{array}{l}\text { 1: Strongly agrees; 0: Agrees / nor agrees nor disagrees / disagrees / } \\
\text { strongly disagrees }\end{array}$ \\
\hline Age & From 20 to 40 \\
\hline Education & $\begin{array}{l}2 \text { dummy variables: high (tertiary education) and low (secondary } \\
\text { education or less) }\end{array}$ \\
\hline Employed & Yes / no \\
\hline In a couple & Yes / no \\
\hline Number of children & From 0 to $\ldots$ \\
\hline Watches news & 1: always; 0 : very often / seldom / never \\
\hline Reads news & 1: always / very often; 0: seldom / never \\
\hline Religious & She goes to church: 1 often / quite often: 0: occasionally / never \\
\hline Political ideology & $\begin{array}{l}\text { From } 0 \text { to } 9 \text { (from left to right), } 3 \text { dummy variables: } 0-4 \text { left, 5-9 right, } \\
\text { missing }\end{array}$ \\
\hline Home owner & Residing in an owned house \\
\hline South & Living in the South (1), in the Centre or in the North $(0)$ of Italy \\
\hline $\begin{array}{l}\text { Aware of the information } \\
\text { provided }\end{array}$ & 1: Yes, I knew everything / most of the things; 0 : I knew little or nothing \\
\hline The message was credible & $\begin{array}{l}\text { 1: Agree / strongly agrees; 0: Nor agrees nor disagrees / disagrees / } \\
\text { strongly disagrees }\end{array}$ \\
\hline $\begin{array}{l}\text { How much she liked the } \\
\text { text / video }\end{array}$ & From 1 to 10 \\
\hline
\end{tabular}


Table A2: Comparison between experimental data and representative Italian data (all women)

\begin{tabular}{lcc}
\hline & $\begin{array}{c}\text { Experimental } \\
\text { data }\end{array}$ & $\begin{array}{c}\text { Representative } \\
\text { Italian data }\end{array}$ \\
\hline Age & 31.7 & 31.1 \\
High educated (\%) & 38.9 & 25.1 \\
Employed (\%) & 61.5 & 51.1 \\
In a couple (\%) & 67.0 & 52.5 \\
Home owner (\%) & 77.4 & 64.8 \\
North of Italy (\%) & 46.7 & 43.5 \\
Centre of Italy (\%) & 20.0 & 19.3 \\
South of Italy (\%) & 33.3 & 37.2 \\
Observations & 1,503 & 5,935 \\
\hline
\end{tabular}

Notes: average values of selected variables calculated using data from the experimental survey (2011) and from the Italian part of the European Survey on Income and Living Conditions (2010). Age and presence of children are defined following the stratification used in the sample selection for the experiment.

Table A3: Comparison between experimental data and representative Italian data (non-mothers)

\begin{tabular}{lcc}
\hline & $\begin{array}{c}\text { Experimental } \\
\text { data }\end{array}$ & $\begin{array}{c}\text { Representative } \\
\text { Italian data }\end{array}$ \\
\hline Age & 29.2 & 28.5 \\
High educated (\%) & 44.8 & 28.8 \\
Employed (\%) & 57.3 & 52.3 \\
In a couple (\%) & 36.1 & 22.9 \\
Home owner (\%) & 77.7 & 69.9 \\
North of Italy (\%) & 44.5 & 43.7 \\
Centre of Italy (\%) & 19.4 & 20.1 \\
South of Italy (\%) & 36.1 & 36.2 \\
Observations & 696 & 3,493 \\
\hline
\end{tabular}

Notes: average values of selected variables calculated using data from the experimental survey (2011) and from the Italian part of the European Survey on Income and Living Conditions (2010). Age and presence of children are defined following the stratification used in the sample selection for the experiment. 